04

\title{
Ловушки в нанокомпозитном слое кремний-диоксид кремния и их влияние на люминесцентные свойства
}

\author{
() П.А. Дементьев, Е.В. Иванова , М.В. Заморянская \\ Физико-технический институт им. А.Ф. Иоффре, \\ Санкт-Петербург, Россия \\ ฯ E-mail: ivanova@mail.ioffe.ru
}

Поступила в Редакцию 15 апреля 2019 г.

В окончательной редакции 15 апреля 2019 г.

Принята к публикации 16 апреля 2019 г.

\begin{abstract}
Исследованы ловушки носителей заряда в термических пленках диоксида кремния и диоксиде кремния с нанокомпозитным слоем, состоящим из оксида кремния и нанокристаллитов кремния, методами кельвинзонд микроскопии и катодолюминесценции. На основании экспериментальных исследований установлено присутствие в образцах ловушек электронов и дырок. Продемонстрированно влияние зарядового состояния ловушек электронов на люминесцентные свойства пленок. Показано, что количество ловушек в нанокомпозитных слоях больше, чем в термических окислах, однако их энергии активации близки по своим значениям. Это говорит о том, что природа ловушек в таких слоях одинакова.
\end{abstract}

Ключевые слова: ловушки электронов, ловушки дырок, нанокластеры кремния, люминесценция.

DOI: $10.21883 /$ FTT.2019.08.47968.454

\section{1. Введение}

Нанокомпозитные слои, представляющие собой слои диоксида кремния с внедренными в них нанокристаллитами кремния, могут применяться как элементы в энергонезависимой памяти [1-3], оптоэлектронике и фотовольтаике [4], в том числе в солнечных элементах третьего поколения [5].

Несмотря на большое количество работ, посвященных исследованию слоев термического диоксида кремния, и диоксида кремния с нановключениями кремния, в данной области остаются неисследованные аспекты. Одним из важнейших недостаточно исследованных вопросов является природа ловушек носителей заряда и их влияние на люминесцентные свойства пленок. Ранее авторами статьи [6-8] была показана возможность формирования нанокомпозитного слоя на поверхности стехиометричного диоксида кремния при высокотемпературном отжиге в азоте. Получаемый нанокомпозитный слой содержит нанокристаллы кремния со средним размером 3-6 nm. Толщина нанокомпозитного слоя зависит от условий отжига, наличия и содержания примесей. Среди наиболее важных свойств нанокомпозитных слоев для практического применения являются их электрофизические свойства, такие как возможности инжекции и сохранения зарядов в пленках. Традиционно такие свойства изучаются при исследовании вольт-амперных и вольт-фарадных характеристик образцов $[9,10]$, но эти методы позволяют исследовать лишь макроскопические свойства слоев. Для анализа локальных свойств диэлектрических слоев и нанокомпозитов необходимы методы, позволяющие определять наличие и транспорт локализованных зарядов, разделять вклад зарядов различных знаков. Следует отметить, что контроль латеральной диссипации заряда в диэлектрических слоях имеет особое значение для современных наноразмерных структур МОП-устройств. В последнее время для изучения локальных свойств диэлектрических слоев активно используется сканирующая кельвин-зонд микроскопия. Известно ее применение при исследованиях тонких $(\sim 15 \mathrm{~nm})$ слоев таких диэлектриков, как $\mathrm{SiO}_{2}, \mathrm{Si}_{3} \mathrm{~N}_{4}$ с внедренными наночастицами различной природы [11], а также органических полевых транзисторов [12,13].

С другой стороны, на возможность использования нанокомпозитных слоев в фотовольтаике большое значение имеют люминесцентные свойства слоев и, особенно, их изменение в зависимости от зарядового состояния люминесцентных центров. Так, в работе [14] было показано, что изменение зарядового состояния ловушек может существенно влиять на люминесценцию оксидных материалов. В связи с этим исследование люминесцентных свойств слоев в зависимости от присутствия ловушек и их зарядового состояния является актуальным и важным для их практического применения.

В настоящей работе проведено комплексное исследование ловушек в нанокомпозитных слоях, полученных на поверхности термических пленках диоксида кремния по сравнению с исходными термическими окислами и их влияние на люминесцентные свойства слоев.

\section{2. Образцы и методы исследования}

\section{1. Образцы}

Были исследованы термические пленки оксида кремния, выращенные на подложках кремния n-типа 
(КЭФ $1.0(111))$ и р-типа (КДБ 0.005 (111)) толщиной $0.42 \mu \mathrm{m}$. Часть образцов была отожжена в атмосфере азота в течение $10 \mathrm{~h}$ для получения нанокомпозитных слоев на поверхности. Ранее было показано, что при этих условиях на поверхности пленки диоксида кремния формируются нанокомпозитные слои с включениями кристаллического кремния со средним размером 3-6 nm. Толщина нанокомпозитного слоя в диоксиде кремния, выращенном на подложке КЭФ, составляла $10 \mathrm{~nm}$, в диоксиде кремния, выращенном на подложке КДБ, $-100 \mathrm{~nm}$. Люминесцентные свойства и структурные особенности слоев до и после отжига были подробно исследованы в работах [6-8].

\section{2. Методы исследования}

\section{Сканирующая кельвин-зонд микроскопия}

Исследования электрофизических свойств образцов проводились методом Кельвин-зонд микроскопии (КЗМ) при помощи атомно-силового микроскопа (АСМ) Ntegra-Aura (NT-MDT, Зеленоград, Москва) в условиях форвакуума $\sim 10^{-2} \mathrm{mbar}$. Использовались стандартные проводящие АСМ зонды с покрытием из карбида вольфрама $\left(\mathrm{W}_{2} \mathrm{C}\right)$.

Использование АСМ позволяет контролируемо менять зарядовые состояния ловушек путем инжекции зарядов непосредственно из АСМ зонда в подложку. В настоящей работе, в отличие, например, от работы [11], инжекция зарядов в образцы производилась не в одной точке, а вдоль линии. При размере изучаемой области $30 \times 30 \mu \mathrm{m}$ длина линии составляла $50 \mu \mathrm{m}$, а время зарядки составляла $\sim 7 \mathrm{~s}$. Выбор такого способа инжекции зарядов связан с достаточно малыми характерными временами диссипации зарядов на некоторых образцах, что делало невозможным корректную регистрацию зарядовых пятен, как в [11].

После создания зарядовых линий производилась регистрация карты поверхностного потенциала. Из анализа профилей полученных распределений определялись электрофизические параметры исследуемых пленок, в первую очередь, коэффициент диффузии зарядов по ловушечным состояниям.

Дополнительно на пленках, выращенных на подложках КЭФ, были проведены исследования зависимости коэффициента диффузии электронов от температуры. Температурный диапазон составлял $300-400 \mathrm{~K}$, что оказалось достаточно для определения энергии активации зарядовых центров.

\section{Катодолюминесценция (КЛ) и измерение поглощенного тока электронного пучка}

Исследования катодолюминесцентных свойств пленок и динамики поглощенного тока электронного пучка проводилось на электронно-зондовом микроанализаторе CAMEBAX (Cameca, Франция) оснащенном оптическим спектрометром оригинальной конструкции для регистрации спектров катодолюминесценции [15]. Измерения спектров катодолюминесценции, динамики интенсивности КЛ и поглощенного тока проводились при энергии электронного пучка $2,5 \mathrm{keV}$, токе электронного пучка $3 \mathrm{nA}$ и диаметре $10 \mu \mathrm{m}$. Глубина проникновения электронов первичного электронного пучка с энергией $2.5 \mathrm{keV}$ в оксид кремния не превышает $90 \mathrm{~nm}$, что позволяет исследовать особенности нанокомпозитного слоя на поверхности пленок. Для обеспечения стока электронов на поверхность образцов была нанесена углеродная пленка толщиной $10-50 \mathrm{~nm}$. Для исследования влияния ловушек на люминесцентные свойства использовалась оригинальная методика, основанная на измерении динамики интенсивности полос катодолюминесценции при непрерывном облучении образцов электронным пучком.

Одновременно с динамикой интенсивности полос катодолюминесценции измерялось изменение от времени величины поглощенного тока электронного пучка. При облучении образцов электронным пучком часть электронов обратно рассеивается от образца, другая часть электронов проникает в образец и передает свою энергию электронной системе образца. Более 90\% энергии первичных электронов, за исключением обратнорассеянных, расходуется на образование электронно-дырочных пар [16]. После торможения избыточный заряд стекает с образца и формирует так называемый поглощенный ток, регистрируемый прибором. Система регистрации тока является стандартной и представляет собой токовый предусилитель, преобразующий ток в напряжение, и подключенную к нему систему индикации. Была разработана специальная система для измерения динамики поглощенного тока. Параллельно системе индикации подключалась схема оцифровки на основе микроконтроллера (МК) ATmega328, подключенного к персональному компьютеру. В качестве опорного напряжения использовался встроенный в МК источник напряжения в $1.1 \mathrm{~V}$, а аналогово-цифровые преобразования производились 10-битовым АЦП. Таким образом, собственная погрешность данной схемы составляла $1 \mathrm{mV}$. Период регистрации тока составлял $1 \mathrm{~ms}$, однако, для повышения соотношения сигнал-шум производилось усреднение по 30 значениям, соответственно, временной шаг измерения значений поглощенного тока составлял $30 \mathrm{~ms}$.

На металлических образцах с высокой электропроводностью наблюдается практически мгновенное (быстрее $1 \mathrm{~ms}$ ) изменение величины поглощенного тока после включения электронного пучка. Однако, если в образце есть ловушки электронов или дырок, то часть носителей заряда может быть захвачена этими ловушками. Этот процесс влияет как на динамику поглощенного тока, так и на динамику интенсивности полос катодолюминесценции, если они связаны с ловушками. Эти процессы наблюдаются при непрерывном облучении образца электронным пучком. Скорость этих процессов может составлять от долей $\mathrm{s}$ до десятков $\mathrm{min}$. 
Таблица 1. Коэффициенты диффузии носителей заряда, инжектированных в приповерхностный слой пленок диоксида кремния, выращенных на различных подложках (КЭФ и КДБ), без нанокомпозитного слоя $\left(\mathrm{SiO}_{2}\right)$ и с нанокомпозитным слоем $\left(\mathrm{SiO}_{2}+\right.$ nanoSi$)$.

\begin{tabular}{c|c|c|c|c}
\hline Тип носителей & КЭФ & КДБ & КЭФ & КДБ \\
(потенциал зарядки) & $\mathrm{SiO}_{2}$ & $\mathrm{SiO}_{2}+\mathrm{nanoSi}$ & $\mathrm{SiO}+\mathrm{nanoSi}^{2}$ \\
\hline Электроны $(-10 \mathrm{~V})$ & $2 \cdot 10^{-10} \mathrm{~cm}^{2} / \mathrm{c}$ & $0.3 \cdot 10^{-10} \mathrm{~cm}^{2} / \mathrm{c}$ & $12 \cdot 10^{-10} \mathrm{~cm}^{2} / \mathrm{c}^{-10}$ & $9.8 \cdot 10^{-10} \mathrm{~cm}^{2} / \mathrm{c}$ \\
Дырки $(+10 \mathrm{~V})$ & $5.7 \cdot 10^{-10} \mathrm{~cm}^{2} / \mathrm{c}$ & $0.7 \cdot 10^{-10} \mathrm{~cm}^{2} / \mathrm{c}$ & $11 \cdot 10^{-10} \mathrm{~cm}^{2} / \mathrm{c}$ & $26 \cdot 10^{-10} \mathrm{~cm}^{2} / \mathrm{c}$
\end{tabular}

\section{3. Результаты и обсуждение}

\section{1. Исследования диссипации заряда методом кельвин-зонд микроскопии}

Были проведены исследования методом КЗМ пленок до и после высокотемпературного отжига. Обнаружено, что на всех образцах происходит изменение зарядовых состояний ловушек путем инжекции в слои зарядов обоих знаков в зависимости от знака внешнего смещения. На рис. 1 приведено характерное изображение изменения распределения поверхностного потенциала во времени после инжекции зарядов из иглы зондового микроскопа в слой диэлектрика вдоль вертикальной линии. Для выяснения работающих в данном случае механизмов диссипации был проведен анализ эволюции профилей распределения потенциалов во времени. Для каждого профиля были определены значение потенциала в максимуме распределения $\varphi$ и ширина распределения на полувысоте $L$.

Известно, что существует два механизма диссипации заряда вдоль слоя диэлектрика [17]. Во-первых, это кулоновское электростатическое расталкивание. Этот механизм характерен для начальных процессов диссипации, когда высока плотность $\rho$ инжектированных зарядов. Электрическое поле $E$ этих зарядов приводит к дрейфовому току зарядов $j_{\text {drift }}=\rho \mu E$, где $\mu-$ подвижность носителей заряда.

Вторым возможным механизмом диссипации является диффузия носителей заряда, тогда диффузный ток зарядов $j_{\text {diff }}=-D \nabla \rho$, где $D-$ коэффициент диффузии. В этом случае размер зарядовой области $L_{\text {diff }}$ должен меняться во времени $t$ по известному закону: $L_{\text {diff }}^{2} \sim D t$.

Как уже говорилось выше, размер зарядовой области оценивался как ширина на полувысоте соответствующего профиля потенциала. Зависимость размера зарядовой области, а также ее квадрата от времени показана на рис. 2. В первую очередь, следует отметить, что уже в начале наблюдения ширина зарядовой линии составляет порядка $2 \mu \mathrm{m}$. Эта величина значительно превышает радиус зонда, который составляет лишь около $70 \mathrm{~nm}$. Одним из наиболее естественных объяснений данного наблюдения являются высокие значения напряженности электрического поля в области иглы (до $10^{8} \mathrm{~V} / \mathrm{m}$ ), под действием которого происходит сильное электростатическое расталкивание инжектируемых зарядов по слою диэлектрика. Из динамики размера зарядовой области видно, что основным механизмом диссипации заряда после инжекции является диффузия носителей заряда по слою диэлектрика. Поле остаточных зарядов составляет менее $10^{6} \mathrm{~V} / \mathrm{m}$, чего, видимо, оказывается недостаточно для эффективного электростатического взаимодействия внедренных зарядов.

Из полученных зависимостей $L_{\text {diff }}^{2}(t)$ были оценены коэффициенты диффузии для носителей обоих знаков в диоксиде кремния без нанокомпозитного слоя $\left(\mathrm{SiO}_{2}\right)$ и с композитным слоем $\left(\mathrm{SiO}_{2}+\right.$ nanoSi $)$. Полученные данные сведены в табл. 1.
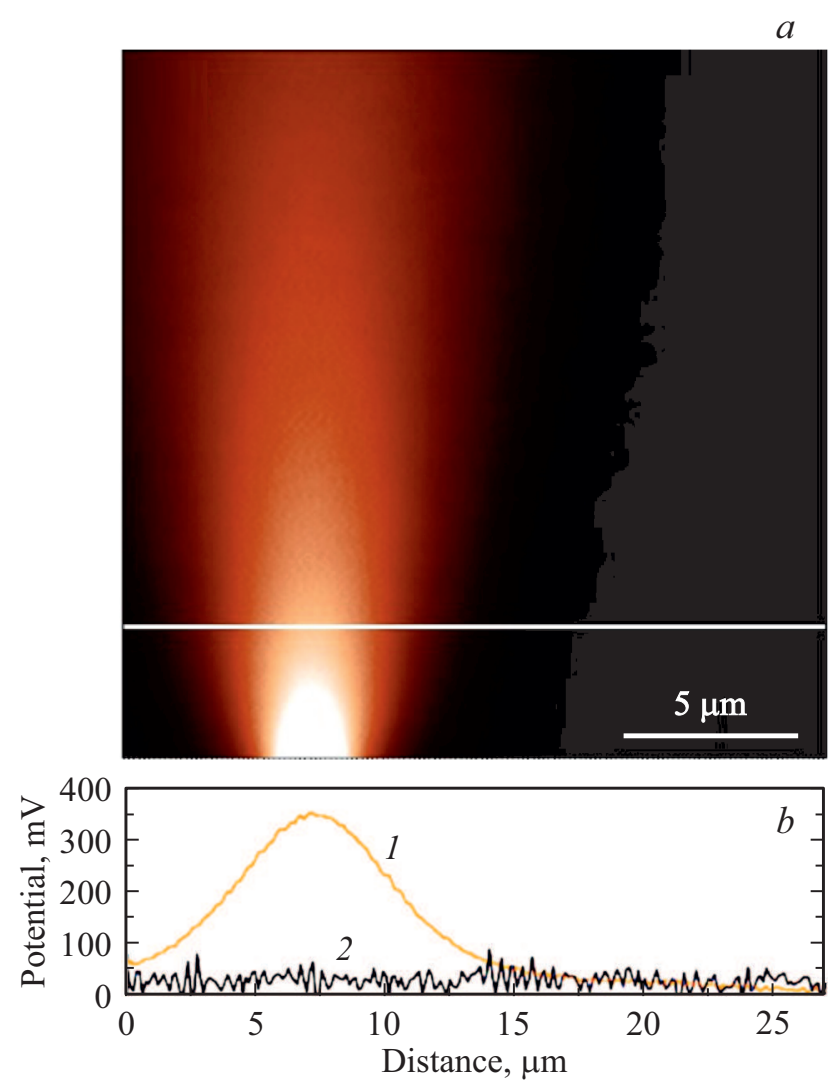

Рис. 1. (а) Изображение изменения распределения поверхностного потенциала во времени после инжекции зарядов из иглы зондового микроскопа в слой диэлектрика вдоль вертикальной линии; $(b)(1)$ профиль распределения потенциала вдоль белой линии на рис. $(a)$, а также характерный профиль распределения потенциала на том же образце до инжекции зарядов $(\times 5)$. 

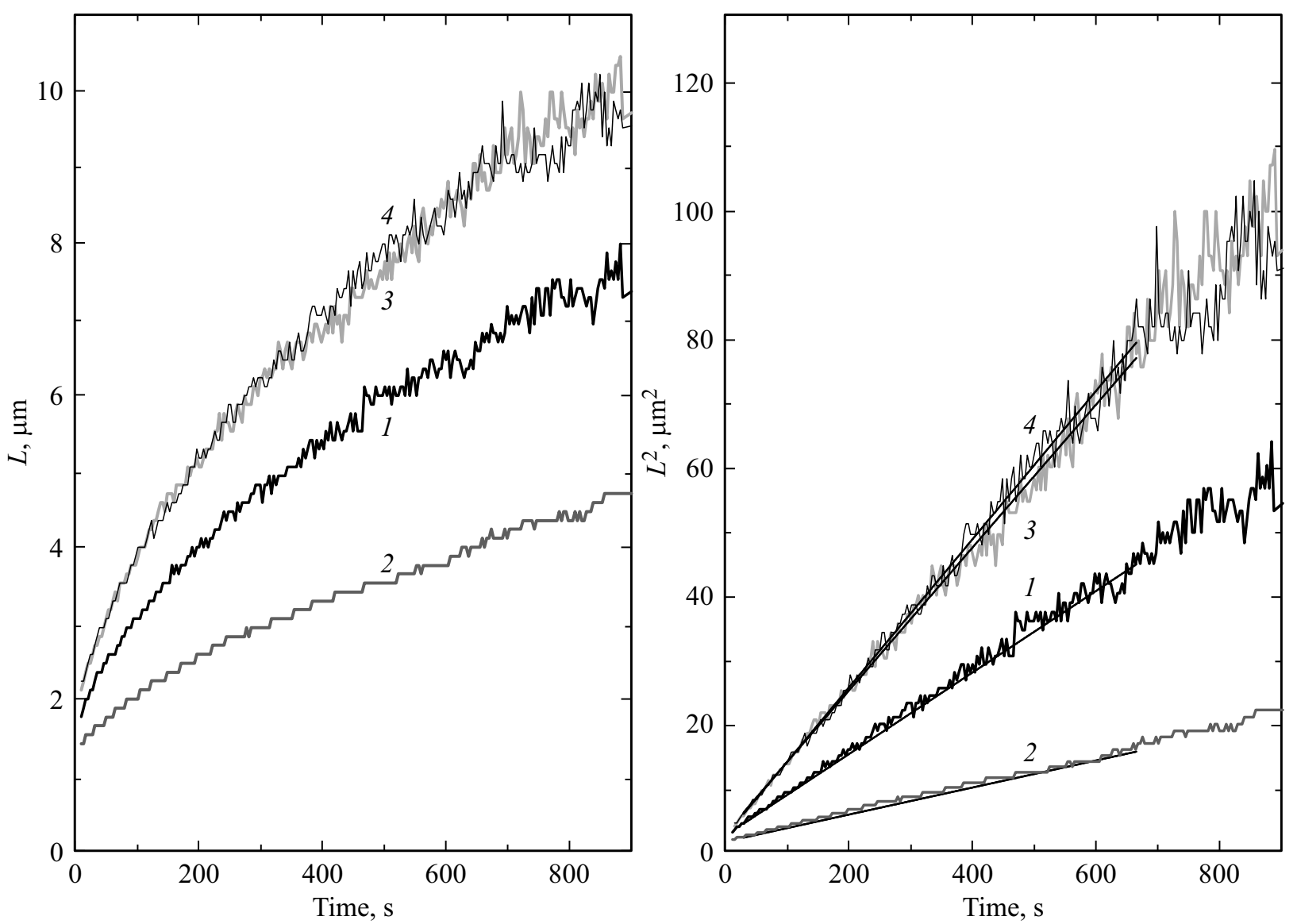

Рис. 2. Зависимость размера зарядовой области $(L)$ и ее квадрата $\left(L^{2}\right)$ от времени для пленки, выращенной на подложке КЭФ, без нанокомпозитного слоя $\left(\mathrm{SiO}_{2}\right)$ и с ним $\left(\mathrm{SiO}_{2}+\operatorname{nanoSi}\right)(3)-$ зарядка $+10 \mathrm{~V},(4)-$ зарядка $-10 \mathrm{~V}$.

Видно, что во всех случаях наличие в слое диэлектрика нанокластеров кремния увеличивает коэффициент диффузии в несколько раз.

\section{2. Исследование динамики поглощенного тока и интенсивности катодолюминесценции}

Была исследована динамика поглощенного тока для всех образцов (рис. 3) при длительном облучении электронным пучком. На исследованных образцах динамика поглощенного тока имеет сложный характер. В пленках, выращенных на подложке КЭФ, наблюдается существенное увеличение тока в процессе облучения электронами. В пленках, выращенных на подложке КДБ, первоначально наблюдается спад поглощенного тока, а затем его рост. Полученные зависимости могут быть объяснены следующим образом.

При облучении образца электронным пучком происходит генерация неравновесных носителей заряда. Если в образце есть ловушки электронов, то с момента начала облучения образца электронным пучком они захватывают электроны. Это приводит к тому, что в начальный момент времени поглощенный ток, измеряемый наноам- перметром, может быть существенно меньше, чем для аналогичного образца без электронных ловушек. При дальнейшем облучении образца электронным пучком ко-

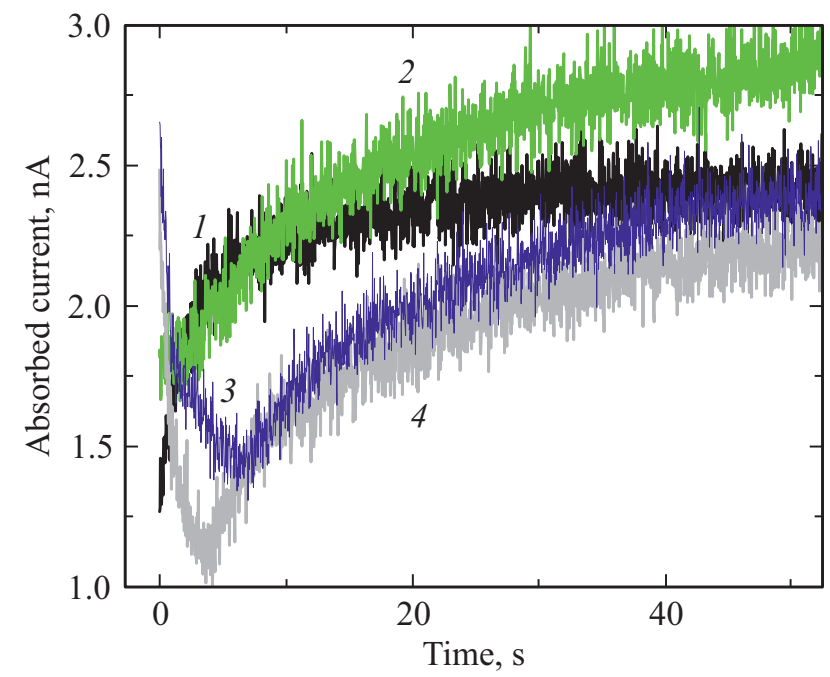

Рис. 3. Зависимость поглощенного тока от времени облучения пленок: выращенной на подложке КЭФ (1) - исходной; (2) - с нанокомпозитным слоем; и выращенной на подложке КДБ (3) - исходной; (4) - с нанокомпонентным слоем. 
Таблица 2. Характерные времена изменения поглощенного тока и времена разгорания КЛ полосы 2.7 эВ

\begin{tabular}{l|c|c|c}
\hline \multirow{2}{*}{ Образец } & \multicolumn{2}{|c|}{ Поглощенный ток } & $\begin{array}{c}2.7 \mathrm{eV} \\
\text { Время } \\
\text { разгорания }(\mathrm{c})\end{array}$ \\
\cline { 2 - 3 } & $\begin{array}{c}\text { Ловушка } \\
\text { для электронов } \tau_{e}(\mathrm{c})\end{array}$ & $\begin{array}{c}\text { Ловушка } \\
\text { для дырок } \tau_{h}(\mathrm{c})\end{array}$ & $6 \pm 2$ \\
КЭФ $\mathrm{SiO}_{2}$ & $6 \pm 1$ & & $18 \pm 2$ \\
КЭФ $\mathrm{SiO}_{2}+$ nanoSi & $16 \pm 2$ & $1.5 \pm 0.5$ & $20 \pm 2$ \\
КДБ $\mathrm{SiO}_{2}$ & $18 \pm 2$ & $2 \pm 1$ & $14 \pm 2$
\end{tabular}

личество свободных ловушек электронов уменьшается, соответственно, происходит увеличение поглощенного тока до стационарного значения, при котором процесс захвата и освобождения электронов компенсируют друг друга. Если в образце имеются ловушки дырок, то в начальный момент после включения электронного пучка поглощенный ток образца может быть выше, чем для аналогичного образца без ловушек дырок за счет образования дополнительных свободных электронов. При дальнейшем облучении образца ловушки дырок будут заполняться, что приведет к падению поглощенного тока до стабильного значения, при котором процесс захвата и освобождение дырок будут компенсировать друг друга. Время изменения поглощенного тока зависит от вероятности захвата носителей заряда ловушками, а относительное изменение величины поглощенного тока с момента включения электронного пучка до его стабилизации пропорционально количеству ловушек. В общем виде зависимости поглощенного тока от времени облучения электронным пучком для образца, содержащего по одному типу ловушек электронов и дырок может быть описано следующим образом:

$$
J=J_{0}-A_{e} \exp \left(-\frac{t}{\tau_{e}}\right)+A_{h} \exp \left(-\frac{t}{\tau_{h}}\right),
$$

где экспонента $A_{e} \exp \left(-t / \tau_{e}\right)$ описывает вклад электронных ловушек, а экспонента $A_{h} \exp \left(-t / \tau_{h}\right)$ - вклад дырочных ловушек. Коэффициенты $A_{e}$ и $A_{h}$ пропорциональны содержанию ловушек в образце, а $1 / \tau_{e}$ и $1 / \tau_{h}-$ вероятность захвата электронов и дырок ловушками соответственно. Следует заметить, что ловушек для носителей обоих знаков может быть несколько типов и, соответственно, экспериментальные зависимости могут быть существенно сложнее.

Для всех образцов были получены спектры КЛ (рис. 4). Спектры КЛ всех пленок содержат полосы, связанные с люминесценцией точечных дефектов: полоса $1.9 \mathrm{eV}$ - немостиковый атом кислорода [18] и $2.6 \mathrm{eV}$ - двухкоординированный кремний с двумя электронами (силиленовый центр) $=\mathrm{Si}$ : [19]. На рис. 4 указаны энергии излучения, для которых были получены временные зависимости интенсивности КЛ от времени при непрерывном облучении образцов электронным пучком. На рис. 5 приведен пример динамики интенсивности полос $2.7 \mathrm{eV}$ и $1.9 \mathrm{eV}$ и поглощенного тока при длительном облучении электронным пучком для термической пленки, выращенной на подложке КЭФ. Результаты обработки динамик интенсивности КЛ полос и поглощенного тока представлены в табл. 2.

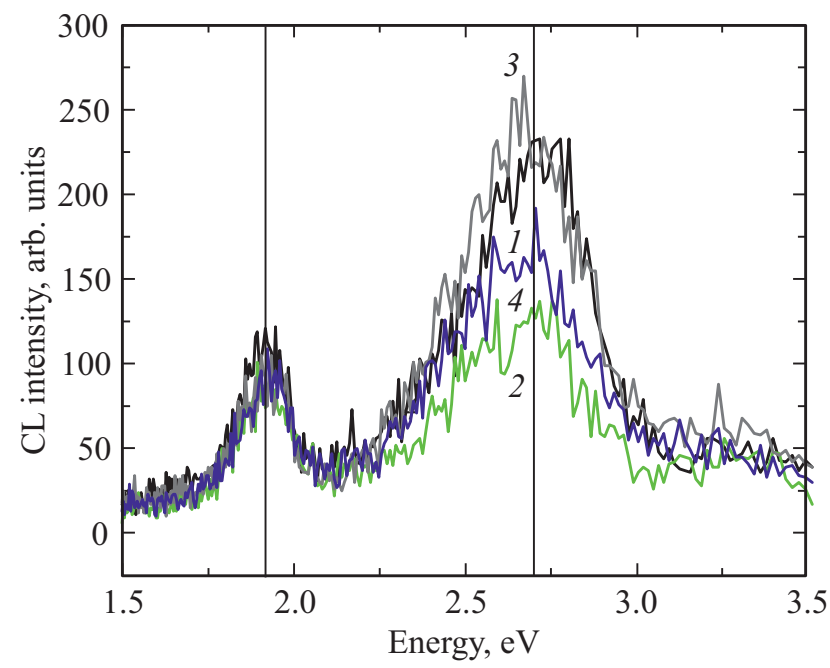

Рис. 4. Спектры КЛ пленок: выращенной на подложке КЭФ (1) - исходной; (2) - с нанокомпозитным слоем; и выращенной на подложке КДБ (3) - исходной; (4) - с нанокомпозитным слоем. На спектрах отмечены спектральные области, в которых были исследованы динамики.

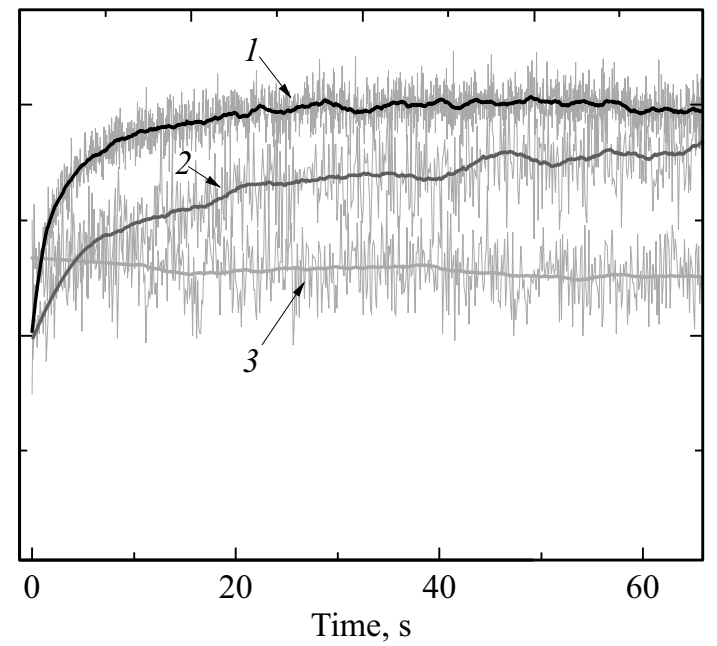

Рис. 5. Зависимость интенсивности полос с максимумом 1,9 эВ и 2,7 эВ и поглощенного тока от времени облучения электронным пучком для пленки на подложке КЭФ до отжига. 
Динамика изменения интенсивности КЛ для термических пленок, выращенных на кремнии $n$-типа КЭФ, хорошо описывалась одной экспонентой, для пленок, выращенных на кремнии р-типа (КДБ) - двумя. Ранее было показано, что изменение интенсивности катодолюминесценции при облучении электронным пучком такой мощности - это обратимый процесс [20], то есть через некоторое время интенсивность в облученной точке возвращалась к прежнему значению. В данных образцах не наблюдалось изменения интенсивности полосы $1.9 \mathrm{eV}$ от времени облучения электронным пучком, что говорит о том, что в данном случае немостиковый атом кислорода не является ловушкой и зарядовое состояние ловушек не влияет на люминесценцию этого дефекта. В то же время видно, что время разгорания полосы $2.7 \mathrm{eV}$ хорошо коррелирует с динамикой поглощенного тока, обусловленной захватом электронов ловушками. Это может быть связано с тем, что силиленовый центр с одним электроном захватывает еще один электрон и становится люминесцентным центром. Так как эти электронные ловушки вносят основной вклад в изменение поглощенного тока, можно предположить, что при исследовании методом кельвин-зонд микроскопии мы наблюдаем также эти же ловушки. Таким образом, мы можем предположить, что основными ловушками электронов в пленках диоксида кремния являются дефекты двукоординированного кремния с одним электроном.

Известно, что при термическом окислении подложек, легированных фосфором, происходит слабое легирование пленки фосфором, тогда как при термическом окислении кремния, легированного бором, легирование пленки уже существенно $[21,22]$. Было рассчитано содержание примесей в пленках на основании статей $[21,22]$. Для пленки на подложке КЭФ 1.0 (111) легирование составило $1.5 \cdot 10^{14} \mathrm{~cm}^{-3}$, для пленки на подложке КДБ 0.005 (111) легирование бором составило $8 \cdot 10^{20} \mathrm{~cm}^{-3}$. Возможно, дырочные ловушки, наблюдаемые в пленках, выращенных на подложке КДБ, связаны с примесью бора. Однако, в этих пленках не наблюдается изменений интенсивности люминесцентных центров с временами порядка $\tau_{h}$, т.е. ловушки дырок не взаимодействуют с люминесцентными центрами. До и после отжига характерные времена захвата ловушек меняются не существенно, что говорит о том, что в процессе отжига увеличивается количество таких центров, но не меняется их природа.

\section{3. Определение энергии активации методом кельвин-зонд микроскопии}

Так как было продемонстрировано существенное влияние электронных ловушек на люминесценцию образцов, были проведены измерения динамики диссипации отрицательного заряда при различных температурах для определения энергии активации электронных ловушек. Для проведения эксперимента были выбраны образцы на подложке КЭФ (n-тип) как наименее легированные. Были проведены измерения, аналогичные вышеописанным, в температурном диапазоне $T=300-400 \mathrm{~K}$. По полученным значениям коэффициентов диффузии, согласно известной формуле

$$
D=D_{0} e^{-\frac{E_{a}}{k T}}
$$

было определено изменение энергии активации $E_{a}$ электронных ловушек после высокотемпературного отжига пленок. Оказалось, что изменение составляет менее $20 \%$, что сопоставимо с ошибкой эксперимента. Показано, что в этих пленках энергия активации электронных ловушек равна $(0.34 \pm 0.05) \mathrm{eV}$. Одинаковая энергия активации подтверждает то, что в пленке диоксида кремния и в пленке диоксида кремния с нанокомпозитным слоем природа ловушек одинакова.

\section{4. Заключение}

В работе проведены исследования процессов зарядки ловушек методом кельвин-зонд микроскопии и по изменению поглощенного тока в электронном-зондовом микроанализаторе. Показано, что во всех пленках диоксида кремния наблюдается зарядка как ловушек электронов, так и ловушек дырок. Исследование изменения люминесцентных свойств в процессе зарядки ловушек позволило предположить, что основными ловушками электронов являются силиленовые центры с одним электроном. Энергия активации таких ловушек, измеренная методом КЗМ, составила $(0.34 \pm 0.05) \mathrm{eV}$. Тот факт, что энергия активации после образования нанокомпозита меняется не существенно позволяет предположить, что присутствие нанокластеров кремния в диоксиде кремния не меняет тип ловушек электронов, а только увеличивается их количество.

\section{Благодарности}

Авторы выражают благодарность О.В. Александрову (СПбГЭТУ „ЛЭТИ“) за предоставленные образцы и помощь в расчете легирования пленок.

\section{Конфликт интересов}

Авторы заявляют, что у них нет конфликта интересов.

\section{Список литературы}

[1] V. Kumar. Nanosilicon, Elsevier (2007) p. 361.

[2] S. Tiwari, F. Rana, H. Hanafi, A. Hartstein, E.F. Crabbe, K. Chan. Appl. Phys. Lett. 68, 1377 (1996).

[3] S.K. Lai. IBM J. Res. Dev. 52, 529 (2008).

[4] L. Khriachtchev. Silicon Nanophotonics: Basic Principles, Current Status and Perspectives, Pan Stanford (2008). 
[5] G. Conibeera, M. Greena, R. Corkisha, Y. Choa, E.-C. Chob, C.-W. Jianga, T. Fangsuwannaraka, E. Pinka, Y. Huanga, T. Puzzera, T. Trupkea, B. Richardsc, A. Shalava, K.-I. Lin. Thin Solid Films 511-512, 654 (2006).

[6] Е.В. Иванова, А.А. Ситникова, О.В. Александров, М.В. Заморянская. ФТП 50, 6, 807 (2016).

[7] E.V. Ivanova, P.A. Dementev, A.A. Sitnikova, O.V. Aleksandrov, M.V. Zamoryanskaya. J. Electron. Mater. 47, 7, 3969 (2018).

[8] Е.В. Иванова, М.В. Заморянская. ФТТ 58, 10, 1895 (2016).

[9] D. Lehninger, P. Seidel, M. Geyer, F. Schneider, V. Klemm, D. Rafaja, J. von Borany, J. Heitmann. Appl. Phys. Lett. 106, 023116 (2015)

[10] E. Yurchuk, J. Muller, S. Muller, J. Paul, M. Pesic, R. van Bentum, U. Schroeder, T. Mikolajick. IEEE Transactions On Electron Devices 63, 9, 3501 (2016).

[11] M.S. Dunaevskiy, P.A. Alekseev, P. Girard, E. Lahderanta, A. Lashkul, A.N. Titkov. J. Appl. Phys. 110, 084304 (2011).

[12] Ze-Qun Cui, Shun Wang, Jian-Mei Chen, Xu Gao, Bin Dong, Li-Feng Chi, Sui-Dong Wang. Appl. Phys. Lett. 106, 123303 (2015).

[13] P.A. Dement'ev, P.A. Alekseev, M.S. Dunaevskii, A.N. Aleshin. J. Phys.: Conf. Ser. 661, 012029 (2015).

[14] K.N. Orekhova, R. Tomala, D. Hreniak, W. Strek, M.V. Zamoryanskaya. Opt. Mater. 74, SI, 170 (2016).

[15] M.V. Zamoryanskaya, S.G. Konnikov, A.N. Zamoryanskii. Instrum. Exp. Tech. 47, 4, 477 (2004).

[16] J. Goldstein, D. Newbury, D. Joy, C. Lyman, P. Echlin, E. Lifshin. Scanning Electron Microscopy and X-Ray Microanalysis. Kluwer Academic/Plenum Publishers, N.Y. (2003). p. 689.

[17] M.M. Perlman, T.J. Sonnonstine, J.A.St. Pierre. J. Appl. Phys. 47, 5016 (1976).

[18] L.N. Skuja, A.R. Silin. Physica Status Solidi A 70, 43 (1982).

[19] H.-J. Fitting, T. Barfels, A.N. Trukhin, B. Schmidt, A. Gulans, A. Von Czarnovski. J. Non-Cryst. Solids 303, 218 (2002).

[20] E.V. Kolesnikova (Ivanova), M.V. Zamoryanskaya. Physica B: Condens. Matter, 404, 4653 (2009).

[21] О.В. Александров, Н.Н. Афонин. ЖТФ 73, 5, 57 (2003).

[22] О.В. Александров, Н.Н. Афонин. ФТП 32, 1, 19 (1998).

Редактор Т.Н. Василевская 